09,01

\title{
Узкополосная люминесценция меди в присутствии наночастиц золота
}

\author{
() М.Е. Компан, С.Е. Никитин, Б.А.-Т. Мелех, А.В. Нащекин
}

Физико-технический институт им. А.Ф. Иоффре,

Санкт-Петербург, Россия

E-mail: kompan@mail.ioffe.ru

(Поступила в Редакцию 6 июня 2017 г.)

\begin{abstract}
Экспериментально обнаружены узкие полосы в спектре излучения меди под слоем наночастиц золота. Излучение возбуждалось Не-Ne лазером (6328 А). Подобные полосы отсутствовали в спектрах пленок отдельных металлов. Приведены условия эксперимента, полученные спектры, обсуждены возможные интерпретации наблюдавшегося эффекта.
\end{abstract}

DOI: $10.21883 /$ FTT.2017.12.45240.184

\section{1. Введение}

Испускание света металлическими материалами обычно достаточно слабое и поэтому мало исследуется (тепловое излучение нагретых тел в данной статье не рассматривается). Причины этого, во-первых, в большой отражательной способности и малой глубине проникновения возбуждения в материал, а, во-вторых, в том, что в металлах отсутствует запрещенная зона и возбужденные носители могут легко рекомбинировать безызлучательно.

Тем не менее, испускание света металлами известно, начиная с работы [1], где описана люминесценция меди и золота. В настоящее время интенсивно исследуются оптические эффекты, связанные с плазмонами в наночастицах высокопроводящих $d$-металлов [2].

Исходно в настоящей работе предполагалось получить усиление комбинационного рассеянного излучения от полупроводникового материала - дисульфида молибдена $\left(\mathrm{MoS}_{2}\right)$, находящегося между медной подложкой и тонкой, полупрозрачной золотой пленкой.

В спектрах свечения таких структур нами были обнаружены несколько узких полос излучения [3]; однако в дальнейшем эксперименты показали, что некоторые из этих полос наблюдаются и без промежуточного полупроводникового слоя. Работа посвящена исследованию обнаруженного свечения меди из-под слоя наночастиц золота. Эффекты, обусловленные прослойкой $\mathrm{MoS}_{2}$, в работе не рассматриваются.

\section{2. Экспериментальная техника и приготовление образцов}

Эксперименты проводились на установке для регистрации спектров рамановского рассеяния света в геометрии рассеяния назад. Основная часть экспериментов выполнена с возбуждением красным светом $\mathrm{He}-\mathrm{Ne}$ лазера $(6328 \AA$ А , 5-10 mW). Свет с образца собирался микроскопом Olympus BX42, в большинстве экспериментов с объективом х20, и анализировался спектрографом Horiba Jobin-Yvon MRS-320 с охлаждаемым CCD детектором. Измерения проводились при комнатной температуре. Ряд контрольных экспериментов был проведен с возбуждением на длине волны $532 \mathrm{~nm}$ на установке LabRam Horiba Jobin-Yvon.

Исследуемые образцы представляли собой фрагменты медной фольги, покрытые тонкими слоями золота.

В качестве подложки использовалась электролитическая медная фольга (99.99\% для печатных плат). В состоянии поставки фольга была защищена полимерной пленкой. Защитная пленка удалялась непосредственно перед нанесением слоя золота. Отсутствие следов органики на фольге проверялось по отсутствию сигнала рамановского рассеяния. Поверхность медной фольги не была зеркально гладкой. Оптическая и атомно-силовая

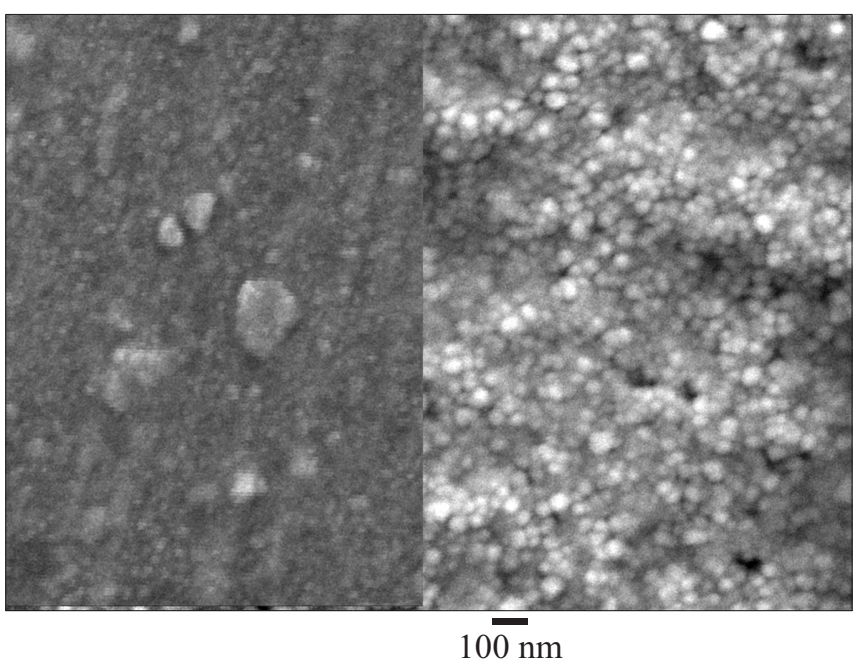

Рис. 1. Микрофотография поверхности пленок золота на меди. Слева - не люминесцирующий образец. Напыление золота на зеркально гладкую медную поверхность. Справа люминесцирующий образец. Напыление на электролитическую фольгу. Отчетливо видно, что поверхность покрыта слоем наночастиц с размерами около $30-40 \mathrm{~nm}$. 
(ACM) микроскопии показали следы прокатки фольги характерные полосы неровностей с высотой порядка микрона.

Слои золота были получены магнетронным распылением при полном давлении в камере $1.4 \mathrm{~Pa}$ и скорости напыления $8-10 \mathrm{~nm} / \mathrm{min}$. В процессе напыления подложки специально не подогревались, и их температура была близка к комнатной. Пленки золота осаждались как на шероховатую поверхность медной фольги, так и на медные подложки с зеркальной поверхностью. Были также получены образцы с отдельными компонентами двухслойных образцов - с медной подложкой, с пленкой золота, нанесенной в аналогичных условиях на другие подложки - стекло и полированный монокристаллический кремний. Средние толщины полученных пленок составляли $10-20 \mathrm{~nm}$.

Поверхность полученных пленок золота была исследована методом сканирующей электронной микроскопии (СЭМ). Для этих исследований использовался сканирующий электронный микроскоп JSM 7001F (Jeol, Япония). Было выявлено, что эти пленки представляют собой слой, состоящий из самосформировавшихся наночастиц золота (рис. 1). Наночастицы имели приблизительно сферическую форму и диаметр в диапазоне $30-40 \mathrm{~nm}$.

Пленки золота, наносившиеся при тех же технологических условиях на зеркально-гладкую медную поверхность, имели иной характер - поверхность не была покрыта наночастицами. Эти пленки не демонстрировали люминесценции.

\section{3. Результаты экспериментов}

Было обнаружено, что в условиях эксперимента двухслойные образцы медь/золото являлись источником оптического излучения. Спектры представляли собой наложение широкой полосы с максимумом около $700 \mathrm{~nm}$ и нескольких узких полос. Как оговаривалось выше, полосы, обусловленные промежуточным слоем дисульфида молибдена, в данной работе не обсуждаются. Наибольший интерес представляют узкие полосы, наблюдавшиеся в спектрах образцов, где пленка золота наносилось на поверхность медной фольги. Типичные спектры такого рода представлены на рис. 2.

На спектрах хорошо видна полоса в области $733 \mathrm{~nm}, \mathrm{c}$ шириной 20-25 nm (FWHM). Эта полоса преобладает в спектре. Ее положение и профиль могли незначительно отличаться от образца к образцу или для разных точек одного и того же образца в пределах указанной полуширины. В то же время намеренное изменение характера поверхности подложки (нанесение подслоя дисульфида молибдена) не влияло заметным образом на эту полосу и не смещало ее за пределы указанной ширины.

В низкочастотной области спектра наблюдалась дублетная полоса, более широкая по отношению к полосе $733 \mathrm{~nm}$, и с меньшей интенсивностью. В том случае, если возбуждение осуществлялось сквозь слой золота, полоса располагалась около $640 \mathrm{~nm}$ (рис. 2). Если же свет возбуждающего лазера был сфокусирован в области края пленки, то дублетная полоса наблюдалась около $650-655 \mathrm{~nm}$ (рис. 2). Аналогичная дублетная полоса $650-655 \mathrm{~nm}$ наблюдалась в условиях эксперимента и просто от медной подложки, без слоя наночастиц золота (рис. 3)

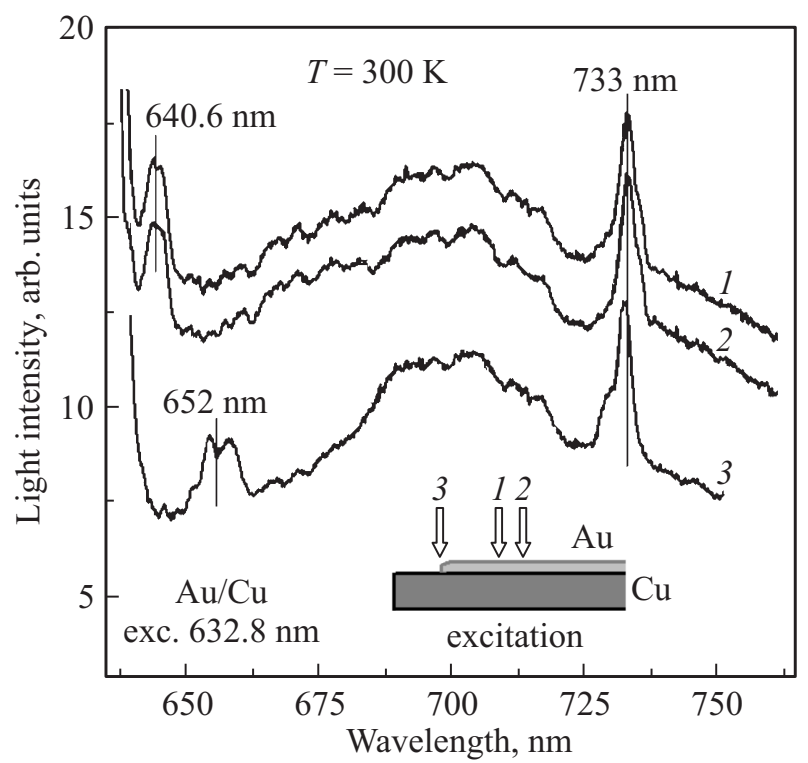

Рис. 2. Спектр высвечивания образца - пленки золота на медной подложке, возбуждение $633 \mathrm{~nm}$. Условия эксперимента в указаны тексте. Два последовательно снятых экспериментальных графика раздвинуты на рисунке, для оценки воспроизводимости. Спектры 1,2 - возбуждение в центральной части пленки, 3 - возбуждение в край пленки.

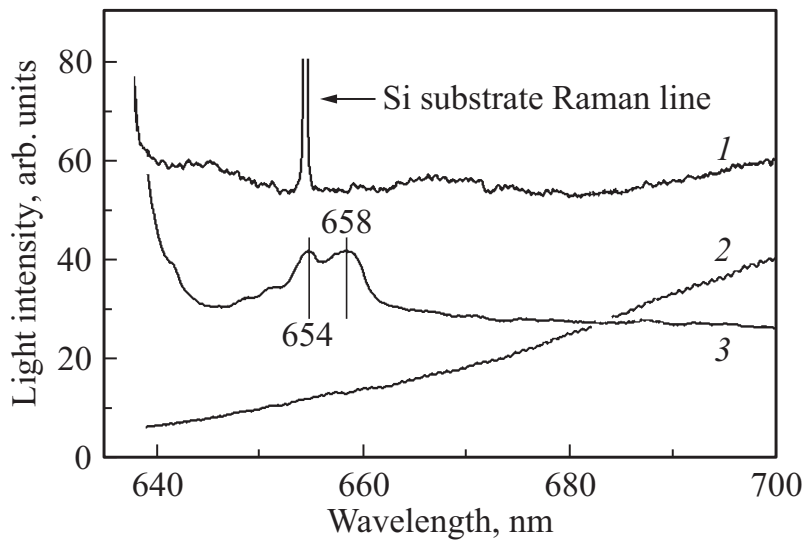

Рис. 3. Спектры свечения отдельных компонент исследуемых образцов: 1 - пленок золота на кристаллическом кремнии, 2 - пленки золота на стекле, 3 - спектр свечения медной фольги-подложки. Хорошо видна линия рамановского рассеяния света кремниевой подложкой, регистрируемая из-под золотой пленки. Указаны положения вершин дублетной полосы, регистрируемой от медной подложки, близко совпадающие по положению с полосами на кривой 3 рис. 2 . 
В контрольных экспериментах проверялась возможность того, что узкие полосы не принадлежат образцу. Регистрировался спектр рассеянного лазерного излучения от матированного прозрачного объекта. Ничего кроме крыла рассеяния света возбуждающего лазера в этом случае не наблюдалось.

Были проведены эксперименты с отдельными компонентами двухслойных образцов - с медной подложкой, c закрывавшей еe защитной полимерной пленой, c пленкой золота, нанесенной в аналогичных условиях на другие подложки - стекло и кристаллический кремний.

Спектры, полученные в дополнительных, контрольных экспериментах показаны на рис. 3. Как уже указывалось, в спектре медной подложки (без Аu пленки) наблюдается дублетная полоса около 650-655 nm.

Напомним, что аналогичная полоса наблюдалась в случае, когда возбуждение осуществлялось в край золотой пленки на меди, по-видимому, из микрообластей, не покрытых пленкой золота. В то же время при возбуждении сквозь центральные области пленки наблюдается близкая по форме и ширине дублетная полоса, расположенная около $640 \mathrm{~nm}$. В этом случае полоса 650-655 nm отсутствует. Значительное смещение обсуждаемой дублетной полосы от положения 650-655 nm в область $640 \mathrm{~nm}$ при покрытии медной поверхности пленкой золота, на наш взгляд, является существенным фактом и должно учитываться при интерпретации природы этой полосы.

Двухслойные образцы, для которых в качестве подложки использовалась зеркально гладкая медь, не свечения не демонстрировали.

Были выполнены опыты по регистрации спектров с возбуждением зеленым лазером с длиной волны $532 \mathrm{~nm}$. Ожидалось, что обнаруженные ранее узкие полосы будут найдены либо на том же расстоянии от линии возбуждения (в единицах $\mathrm{cm}^{-1}$ ), либо на том же месте спектра в длинах волн $(\mathrm{nm})$. Это позволило бы однозначно интерпретировать их соответственно как полосы в спектре рассеяния или люминесценции. Однако спектры, зарегистрированные в эксперименте с возбуждением $532 \mathrm{~nm}$, не соответствовали ни тому, ни другому случаю. При возбуждении на длине волны $532 \mathrm{~nm}$ была зарегистрирована широкая полоса и на ее фоне одиночная узкая полоса около $575 \mathrm{~nm}$. Таким образом, имеющиеся экспериментальные результаты не позволяют с абсолютной достоверностью интерпретировать наблюдавшиеся узкие полосы как проявление люминесценции или рамановского рассеяния.

\section{4. Обсуждение результатов}

Как показано во многих работах, присутствие наночастиц благородных металлов на поверхности может приводить к усилению собственного свечения материалов на несколько порядков. В частности, на этом основываются методики, использующие эффекты SERS и TERS [4-6]. При этом нужно учитывать, что усиление свечения при плазмонном резонансе связано с локальным увеличением интенсивности электромагнитного поля и не может являться критерием для отделения люминесценции от рамановского рассеяния. Поэтому при анализе следует иметь в виду оба эти эффекта.

Наиболее простой возможностью объяснить наблюдаемые полосы было бы предположение о посторонних наслоениях на поверхностях исследуемых образцов. Однако против такого предположения свидетельствуют результаты опытов с пленками, состоящими из одиночных металлов.

Кроме случайных неопределенных загрязнений, необходимо рассмотреть возможность того, что новые полосы как-то связаны с окисными пленками на золоте и меди. Ширины запрещенных зон окислов меди $\mathrm{CuO}$ и $\mathrm{Cu} 2 \mathrm{O}$ приведены, например, в [6,7]: 1.2 и $2.137 \mathrm{eV}$ coответственно. Положения наблюдавшихся полос $733 \mathrm{~nm}$ (или $2150 \mathrm{~cm}^{-1}$ - если бы линия была обусловлена рассеянием) и $640 / 650 \mathrm{~nm}\left(290 / 550 \mathrm{~cm}^{-1}\right)$ не соответствуют по положению возможной краевой люминесценции этих окислов.

Образование оксидов золота в условиях напыления пленок, сходных с нашими, описано в литературе [8]. Это материалы с высокой электропроводностью. В работе [9] рассчитаны зонные структуры этих материалов и оценены частоты решеточных колебаний, которые оказываются много ниже частоты зарегистрированной линии $733 \mathrm{~nm}\left(2150 \mathrm{~cm}^{-1}\right)$. Сообщения о люминесценции оксидов золота нами не найдено. Свечения пленок, нанесенных на иные подложки, кроме использовавшейся $\mathrm{Cu}$-фольги, нами не зарегистрировано. Все это позволяет считать маловероятным, что в нашем эксперименте проявляется свечение окисных пленок или загрязнений.

Рассмотрим возможную природу узких полос, наблюдающихся в спектре.

Полоса около $733 \mathrm{~nm}$ не наблюдалась в спектрах пленок отдельных металлов, хотя она присутствовала в спектрах всех образов, у которых золото наносилось на поверхность медной фольги. Кроме того, полоса $733 \mathrm{~nm}$ практически без изменения амплитуды и ширины наблюдалась и в спектрах образцов с промежуточным слоем (Cu-фольга/ $\left.\mathrm{MoS}_{2} / \mathrm{Au}\right)$, что указывает на слабую чувствительность этой полосы к загрязнению поверхности. Более того, для более толстых пленок золота относительная интенсивность этой полосы в спектре возрастала. По совокупности данных можно предположить, что эта полоса обусловлена люминесценцией собственно наночастиц золота. Такое предположение опирается и на то, что сообщения о люминесценции и электролюминесценции золота имеются в научной периодике $[10,11]$. Отсутствие люминесценции пленок золота, нанесенных на зеркально гладкие подложки (стекло и кремний) объяснимо гладкостью получаемых в этом случае слоев (рис. 1) и соответственно отсутствием усиления поверхностью. 
Наиболее примечательным фактом представляется обнаруженное смещение второй узкой полосы между положениями $650-655 \rightarrow 640 \mathrm{~nm}$ при нанесении слоя золотых наночастиц. Основываясь на близости интенсивностей и ширин этих полос, а также на их характерных профилях, можно предположить, что упомянутые выше полосы обусловлены переходами между одними и теми же (или близкими) уровнями, участвующими в излучательной рекомбинации. Поскольку полоса 650-655 nm наблюдалась для исходной медной подложки, обе эти полосы следует приписать излучению меди.

Значительная величина обнаруженного сдвига - более $10 \mathrm{~nm}$, что вдвое превышает ширину полос, по всей вероятности, свидетельствует о том, что полоса возникает не из-за неупругого рассеяния света. Такой сдвиг частоты решеточных колебаний (порядка $200 \mathrm{~cm}^{-1}$ ) в материале означал бы экстремально сильную деформацию меди при напылении слоя наночастиц, что маловероятно. В то же время нанесение слоя наночастиц легко могло привести к появлению дополнительных поверхностных уровней или к перезарядке существующих, что, в свою очередь, внесло бы изменение в систему излучающих уровней и к изменению частоты света люминесценции.

Механизмы, приводящие к появлению в спектре обсуждаемых полос, можно предложить. основываясь на моделях люминесценции благородных металлов, предложенных в [12-14]. В соответствии с этими моделями, свет возбуждения поглощается на переходе из $d$-зоны в сложную $s-p$ зону проводимости. В зоне проводимости возбужденные фотоэлектроны релаксируют по энергии примерно до уровня Ферми, где частично захватываются на поверхностные уровни, а затем рекомбинируют с дыркой в $d$-зоне.

Существенным следствием этих моделей является то, что полосы высвечивания не привязаны к минимумам зоны проводимости, а их положение меняется с изменением энергии фотона возбуждения. Для более коротковолнового возбуждения и люминесценция лежит в области более коротких длин волн. При этом разность энергий фотона возбуждения и фотона высвечивания не соответствует какой-либо характерной энергии исследуемого материала (например, энергии фонона, как это было бы в случае рамановского рассеяния). Такое поведение люминесценции согласуется с результатом наших экспериментов, со сравнением результатов опытов с возбуждением на разных длинах волн. Нанесение пленки золота на медную подложку может менять положения и/или заселенности уровней в приконтактной области меди, из которой и исходит свечение. Это может объяснить обнаруженный сдвиг полосы 650-655 nm.

Таким образом, по совокупности экспериментальных фактов и аргументов следует считать, что обнаруженные узкие полосы обусловлены люминесценцией металлов: меди и золота.

Отдельно следует упомянуть, что лежащее в основе наблюдавшихся эффектов самоформирование золотых наночастиц представляется весьма интересным и перспективным для получения SERS-активных подложек. В нашем случае, как показывает прямое наблюдение, самоформирование обусловлено не условиями напыления (они были одинаковые для зеркальных и негладких подложек), а рельефом подложки. Такое наблюдение совпадает с выводами работы [15], в которой было показано, что формирование кластеров напыляемого материала облегчается для подложек с негладким рельефом. Более детальное обсуждение этого явления выходит за рамки данной работы.

\section{5. Выводы}

Обнаружено узкополосное излучение на образцах меди, покрытых слоем наночастиц золота. По совокупности аргументов сделано предположение, что наиболее интенсивная полоса $733 \mathrm{~nm}$ соответствует люминесценции наночастиц золота, а наблюдающееся свечение в 640/655 nm представляет собой люминесценцию, отвечающую межзонной рекомбинации $4 s p \rightarrow 3 d$ в медной подложке, (соответственно свободной или покрытой слоем наночастиц золота). Характеристики наблюдавшегося свечения согласуются с положениями известных публикаций по данной теме.

Авторы благодарны А.В. Анкудинову за анализ рельефа поверхности методом АСМ, а В.А. Левицкому за проведение оптических экспериментов с возбуждением на длине волны $532 \mathrm{~nm}$.

Электронно-микроскопические исследования выполнены на оборудовании Федерального ЦКП „Материаловедение и диагностика в передовых технологиях“ при ФТИ им. А.Ф. Иоффе.

\section{Список литературы}

[1] A. Mooradian. // Phys. Rev. Lett. 22, 185 (1969).

[2] Y.-H. Su, W.-L.Wang. Nanoscale Res. Lett. 8, 408 (2013).

[3] M.E. Kompan, B.A.-T. Melech, S.E. Nikitin. arXiv:1702.05476.

[4] Surface enhance Raman scattering / Ed. R.K. Chang, T.E. Furtak. Plenum Press, N.Y. (1982).

[5] M.D. Sonntag, E.A. Pozzi, N. Jiang, M.C. Hersam, R.P. Van Duyne. J. Phys. Chem. Lett. 5, 18, 3125 (2014).

[6] S.Y. Choi, Ch.T. Yip, G.-C. Li, D.Y. Lei, K.H. Fung, S.F. Yu, J. Hao. AIP Advances 5, 067148 (2015).

[7] https://en.wikipedia.org/wiki/Copper(II)_oxide

[8] https://en.wikipedia.org/wiki/Copper(I)_oxide

[9] V. Dolique, A.-L. Thomann, E. Millon, A. Petit, P. Brault. Appl. Surf. Sci. 296, 184 (2014).

[10] H. Shi, R. Asahi, C. Stampfl. Phys. Rev. B 75, 205125 (2007).

[11] J.I. Gonzalez, T.-H. Lee, M.D. Barnes, Y. Antoku, R.M. Dickson. Phys. Rev. Lett. 93, 14, 147402 (2004).

[12] J. Zheng, C. Zhang, R.M. Dickson. Phys. Rev. Lett. 93, 7, 077402 (2004).

[13] M. Pattabi, R.M. Pattabi. Nano Hybrids 6, 1 (2014).

[14] S.K H. Andersen, A.L. Pors, S.I. Bozhevolnyi. ACS Photonics, 2, 2, 432 (2015).

[15] O.K. Alexeeva, V.N. Fateev. Int. J. Hydrogen Energy 41, 3373 (2016). 